\title{
Health Promotion Among Individuals Facing Chronic Illness: The Unique Contribution of the Bodyknowledging Program
}

\author{
Kristin Heggdal
}

\begin{abstract}
This chapter offers an oversight of the concept of chronic illness and the meaning of health promotion in this context. Bodyknowledging is a theory describing patients' process of health promotion in chronic illness that has been used as a theoretical frame for a new health intervention; the Bodyknowledging Program (BKP). This program is outlined as the aim of BKP is to activate and strengthen patients' resources for health in chronic illness. Outcomes for patients and implications for practice are discussed.
\end{abstract}

\section{Keywords}

Chronic illness $\cdot$ Health intervention $\cdot$ Patient participation $\cdot$ Health $\cdot$ Well-being

\subsection{Introduction}

The concept of health promotion has traditionally been associated with preventive measures for healthy people, while health promotion in relation to people already diagnosed is a relatively new idea which is scarcely described in the literature.

K. Heggdal $(\bowtie)$

Lovisenberg Diaconal University College,

Oslo, Norway

e-mail: Kristin.Heggdal@ldh.no
The goal of health promotion is to increase the involved persons' control over their health and to improve it. This includes people diagnosed with chronic illness and involves mobilizing strengths for the promotion of health and well-being [1].

\subsubsection{The Concept of Chronic Illness}

Although there is no universal consensus about the definition, it is common to apply the term chronic illness when there is a disease with a prolonged trajectory for which there is no curative treatment, and when the condition impacts the persons' life and functioning and requires monitoring and specific management measures [2]. Chronic illness falls under the heading of noncommunicable diseases (NCD), which encompasses a large group of illnesses, such as diabetes, hypertension, stroke, heart disease, pulmonary conditions, cancer, and mental health conditions. The term may also include selected communicable diseases such as HIV [3]. Chronic illness occurs across the lifespan. Due to the advent of new options for treatment, improved disease management, and improved living conditions, children diagnosed with chronic illness are increasingly surviving into adulthood. Similarly, people who would previously have significantly shortened lifespan due to chronic illness are now experiencing increased longevity [4]. 
Chronic illness is one of the leading healthrelated challenges across the world and currently the main cause of both death and disability worldwide $[4,5]$. The majority of conditions contributing to mortality and morbidity combined in high-income countries like Europe, USA, and Australia include ischemic heart disease, stroke, lung cancer, depression, diabetes, and back and neck pain. In low-income countries like countries in Africa and middle-income countries like China, the major conditions contributing to mortality and morbidity include stroke, diabetes, and depression, and also communicable diseases such as diarrhea, HIV, and malaria, and road traffic injuries [6].The risk of coronary disease, ischemic stroke, diabetes, and cancer increases steadily with increasing body mass index (BMI) and obesity, which has become a major health concern, especially in high- and middle-income countries. In addition, the Institute for Health Metrics Evaluation reports that the number of people suffering from mental illness is relatively large but stable, as one in four people in the world will be affected by mental of neurological disorders at some point in their lives. The prevalence increases with age, but high rates of comorbidity has also been reported in working-age populations [7]. Many patients attending health care today have two or more chronic conditions. In Europe, it has been estimated that multimorbidity (or comorbidity) affects up to $95 \%$ of the primary care population aged 65 years and older. Approximately $25.5 \%$ of the United States population report to have more than one chronic condition, and the prevalence increases to $50 \%$ of adults 45-65 years, and up to $81 \%$ of adults older than 65 years. For adults over 50 years, rates of multiple chronic disease will vary from $45 \%$ in China to $71 \%$ in Russia [6].

About half of the individuals with comorbid chronic conditions report functional limitations and are more likely to have poor self-reported health; therefore, effective interventions are necessary to optimize health outcomes in the presence of chronic illness [8]. While medical treatment can contribute to the reduction of symptoms and to prevention of complications, sometimes no treatment is available. Addressing comorbidity, including mental health problems, emphasizes the importance of developing interventions that attend to the person's health as a whole [5]. Such interventions call for an understanding of patients as resourceful partners for health together with professionals and peers.

\subsection{Health Promotion in Chronic Illness}

According to Larsen [2], health promotion in chronic illness involves "efforts to create healthy lifestyles and a healthy environment to prevent secondary conditions, including teaching individuals to address their health care needs, increasing opportunities to participate in usual life activities and striving for optimal health. These secondary conditions may include the medical, social, emotional, mental, family, or community problems that an individual with a chronic or disabling condition is likely to experience (p. 367)." While professionals' treatment and care are significant, patients have an important role in learning as much as possible about their conditions and becoming involved in the management of their disease, in prevention of future relapses and in health promotion efforts. This includes taking part in communication with health professionals on health-related matters as well as efforts to avoid risk factors such as poor nutrition, lack of physical activity, smoking, alcohol abuse, and social isolation, because the same risk factors that cause a chronic condition can also make it worse.

It is important to increase patients' ability to manage their conditions and to maintain or improve their levels of functioning [2, 4, 9]. Manageability, comprehensibility, and meaningfulness constitute dimensions of the persons' Sense of Coherence (SOC) and represent central assets for health as they reflect the ability to understand one's existence as organized and the belief that one has the ability to handle one's life and to reestablish meaning while facing chronic conditions [10, 11]. Studies involving patients with chronic illness confirm that patients who have a strong SOC have a greater capacity to manage their chronic illness [12, 13]. For people 
who live with chronic illness and their supporters, health promotion is a process of enabling and developing potentials for healing and health. By this means it affords new strategies and actions to strengthen hope among sufferers, to reduce their anxieties, and to facilitate a meaningful life (Chaps. 7 and 8). Its goal is to increase the capacity of people to deal with the consequences of chronic illness and to ensure that this experience does not dictate their lifestyle. The potential for activities for the strengthening of overall health remains largely untapped in many individuals with chronic illness and finding new ways of accomplishing health promotion often remains an unfilled goal for health care professionals and their chronically ill patients. Determining chronically ill individuals' perceptions of their condition, their aspirations, and their available resources, and supporting their effort to achieve health promotion is an ongoing process. Efforts must go beyond the individual's chronic illness and limitations to include holistic health that focuses on personal goals, evidence-based treatment and care tailored to the person, and a willingness to adjust a plan as needed [2]. Self-care combined with health promotion efforts conducted together with health care providers (and peers) is necessary to optimize health outcomes [14]. Self-care involves both the ability to care for oneself and the performance of activities necessary to achieve, maintain, or promote optimal health [15]. Qualitative studies of the meaning of self-care to patients have identified themes such as "body listening" and monitoring "bodily cues," managing social context and lifestyle, having control over treatment, taking care of and not harming oneself [15-17]. Self-care is, therefore, an essential part of health promotion in chronic illness [18].

Summaries of research concerning people with various long-term conditions confirm that they have a lot in common as they face the challenges of trying to live as well as possible within the physical, mental, or social discomfort and limitations [2, 19, 20]. Powerlessness is an essential part of the illness experience and impose challenges for both person and family
$[2,21]$. However, research findings also indicate that people who are diagnosed with chronic illness possess resources and strategies for health that are not fully recognized and capacities for health that is not sufficiently utilized in the current health system [22-24].

Mobilizing patients' intrinsic resources and capabilities for health in chronic illness to be used alongside medical expertise and care will require new interventions to be applied across age, gender, diagnostic categories, clinical settings, and health systems. Such interventions will reflect the philosophical perspective of "health within illness," which holds that individuals living with long-term health problems are capable of experiencing health and well-being despite their conditions [10, 24, 25]. This perspective fits well with the philosophy of empowerment (Chap. 13) and with the key papers from WHO's Health for All 2000 series [26], which emphasizes individuals gaining control over their lives and their health and the importance of active participation. Individuals who are actively involved are likely to experience at least some degree of control, and there is an assumed relationship between degrees of participation, empowerment, and health.

Empowerment programs imply active participation and can lead to improved health outcomes for individuals like improved self-efficacy, greater sense of control, increased knowledge and awareness, behavior change and greater sense of community, broadened social networks, and social support [27].

Health promotion, with respect to chronic illness then, requires the joint action of those living with illness, their significant others and professionals that exchange their experience and knowledge, including the patients' experiencebased knowledge of how best to live with chronic illness [9, 22, 23]. However, health professionals seem to base their practice on the logics of traditional medicine and expert knowledge on compliance and not on what the individual (patients) themselves see as a better life [28, 29]. Wagner et al. [30] argue that there is a need for improving practice by means of interventions that allow for person-centered approaches that provide suf- 
ficient support for individuals to take charge of their own health. "Person-centeredness" is underpinned by values of respect for persons, individual right to self-determination, mutual respect, and understanding. It is enabled by cultures of empowerment that foster continuous approaches to interprofessional practice development [31]. There is a need for interventions that can operationalize the philosophy of patient-centeredness in such a way that the patients' potentials for health is activated and strengthened. In the next section, a new health promotion intervention in chronic illness is presented. The intervention was developed in close cooperation with patients and health professionals in clinical practice in specialist and community care settings in Norway.

\subsubsection{The Bodyknowledging Program (BKP): An Innovative Approach for Health Promotion in Chronic Illness}

The Bodyknowledging Program (BKP) is a person-centered health intervention for the strengthening of self-care, health, well-being, and empowerment in chronic illness [32]. This approach challenges current practice in the sense that the focus is not primarily on the problem of chronic illness, lifestyle, or behavioral change nor the methods used by professionals. Instead, the participating patients' experiences, their strengths, and capabilities is taken as the point of departure, while the challenges imposed by illness is a backdrop to search for possibilities for health within illness. In the following sections, the theoretical foundation, structure, content, and means of the intervention are outlined.

\subsubsection{Theoretical Framework for the Intervention}

The grounded theory of Bodyknowledging $[23,33,34]$ serves as the main conceptual framework for the intervention (Fig. 16.1). Bodyknowledging theory asserts that people have bodily knowledge that constitute an impor- tant but little used resource for health in chronic illness. Bodyknowledging was defined as "a fundamental process for the development of personal knowledge about one's body, coping skills, health and wellbeing [23]." Patients' bodily knowledge of health and illness is multidimensional, consisting of personal knowledge of one's limits and tolerances of the type and amount of activity; physical and psychosocial factors in their environment that have a positive or negative impact on the condition; and personal knowledge of symptoms of relapses, and the actions, interactions, and social contexts that contribute to recovery, health, and well-being [34]. It is an inherent and often tacit type of knowledge, often expressed in action i.e. in the affected persons' competence of self-care, self-management, and strategies for wellness.

Bodyknowledging theory elicits that persons' embodied knowledge is developed as a resource for health through a basic psychosocial process in interaction with the environment. The process is constituted by four phases: Uncertaintyescaping the sick body; Losing life space, grieving, and anger; Listening and understanding the body's signs — strengthening hope; and Integrating embodied knowledge-new possibilities for wellness and health [33]. It is a challenging process of learning to live with health problems, understanding the changes and developing strategies for health. Figure 16.1 serves to visualize this process.

Chronically ill patients' process of Bodyknowledging is dynamic and nonlinear as they are moving up and down, in and out of different phases while building "a bridge" between pre-illness life and their life with health-related challenges. This is in line with a salutogenic orientation [10] in the sense that health is perceived as a flexible continuum. Consequently, persons living with health problems may have different degrees of health according to where they are in their process, and the movement up and down, in and out of phases is a normal and necessary part of the persons' health promoting process. Shifting perspectives between having 


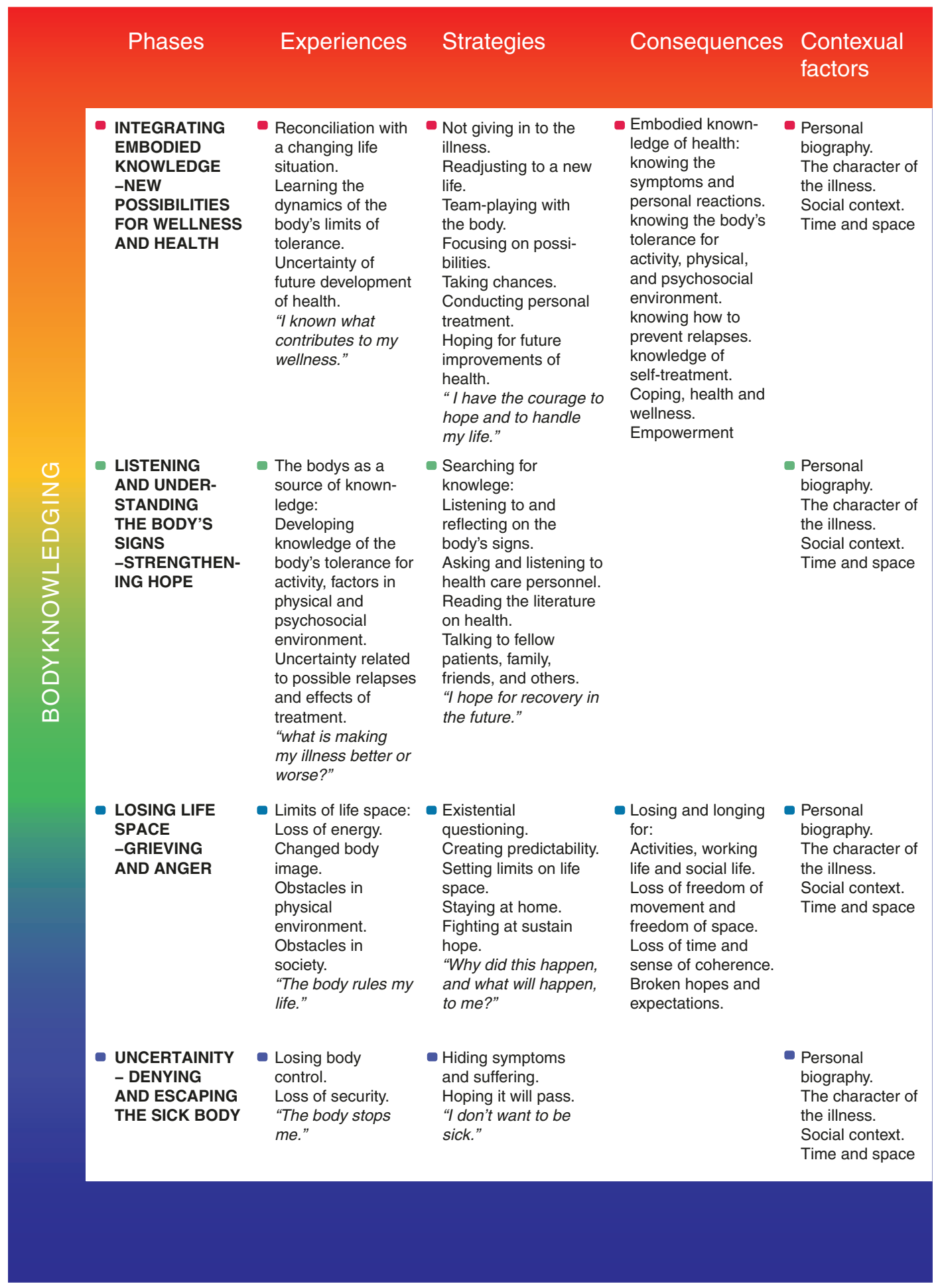

Fig. 16.1 Bodyknowledging theory: patients' process of health promotion in chronic illness 
illness or health in the forefront is a part of the process [19]. Therefore, Bodyknowledging is to be understood as an ongoing process and activity in which knowledge of new possibilities for health and well-being is developed and continually renewed. Varied and flexible strategies for the promotion of health are developed through the process, such as not giving in to the illness, readjusting to a new life, team-playing with the body, focusing on possibilities, taking chances, preventing relapses, conducting personal treatment, and hoping for future improvement of health. Strategies are individually expressed and specific to the situation.

Patients' personal process of health promotion goes on even if the illness at times pose obstacles that seem to be hard to handle. The Bodyknowledging process (Fig. 16.1) elicits the danger of the person being trapped in the experiences of uncertainty, losses of life space, grieving, and anger. In such cases, the process is being changed in a pathogenic direction. These groups of patients are exactly those who need an intervention such as the Bodyknowledging Program in order to learn how to move towards the healthy pole again.

Bodyknowledging theory is in line with the phenomenological understanding of the body as introduced by Merleau-Ponty [35, 36] in which the body is understood as an object and subject at the same time and as a primary source of knowledge. The dialectics of the body as subject and object are being used in the person's efforts to promote health when they observe their body and at the same time sense its reactions. In BKP, this dialectic function of the body is being utilized in the physical exercises as well as in the structured dialogue.

The theoretical basis for the intervention also rests on Freire's pedagogical theory of the oppressed [37], which asserts that the person's acknowledgement of their situation and efforts to find solutions is groundbreaking, and that dialogue is a means for the liberation of human resources. More details on the theoretical foundation has been published elsewhere [32]. The next section offers an overview of the intervention components.

\subsubsection{Structure, Content and Pedagogical Approaches of the Bodyknowledging Program Intervention (BKP)}

The Bodyknowledging Program is a broadly applicable intervention designed for people living with a variety of chronic illnesses. The objective is to facilitate participants' efforts of prevention of deterioration, their capacity for health as well as their possibilities to participate in society [32] by acknowledging and strengthening patients' unique yet undervalued bodily knowledge in chronic illness [23]. The phases described in the layperson-based concepts of Bodyknowledging is used as "process tools" to promote patients' capability for health. This idea is incorporated in the program structure, in the content, and in the pedagogical approaches.

\subsubsection{Structure}

The program is organized in group format consisting of 7 sessions over 12 weeks and conducted in co-ed groups of 8-10 participants diagnosed with a variety of long-term chronic illnesses. This mode of organization aims to facilitate the participant's systematic work on their health over time.

There is one 3-h session (with a 30-min break to eat and socialize) every week during the first 3 weeks. Sessions 4-6 are held every second week, and the final session is held in week 12. Two health care professionals (HCP) representing two different professions (e.g., one nurse paired with one physiotherapist or occupational therapist) receive 40 contact hours +40 self-study hours of specialized training before they engage as course leaders in the program. BKP is accomplished in groups mixed with men and women having different kinds of diagnoses as this was found to be broadly applicable across diagnosis, ages, sexes, and clinical sites through clinical trials in Norway [38]. Active patient participation was fundamental in the development of the intervention and is a prerequisite for program completion in practice.

\subsubsection{Content}

The content is organized according to the phases of Bodyknowledging [33] described by former 
patients [23, 33, 34] and used as a tool to support the participants whereby professionals invite participants to work on the uncertainty, losses of life space, grieving and anger, listening and understanding the body's signs and the integration of knowledge on new possibilities for well-being and health [23] (s. 16.1). The Bodyknowledging program constitutes a "room for recovery" in which patients can share their narratives about their health condition and strategies for health and wellness with HCP and peers. In this way, the participating patients contribute to constitute an essential part of the content followed by HCP's questions to facilitate reflection on the person's health promotion efforts. This is in line with empowerment models of health promotion [39] as it aims to facilitate action by raising critical consciousness of one's own health while highlighting factors that are subject to change based on actions relevant to the person. Patient's relationship to, and interaction with, significant others is an important part of the program content as these relations may represent both assets and challenges to patients' health promotion efforts.

\subsubsection{Pedagogical Approaches}

The pedagogical approaches in BKP aim at activating and facilitating patients' inherent resources for health. Dialogue and posing open questions are essential pedagogical approaches in this regard. Bodyknowledging theory is a tool in this regard as it offers a structure for the dialogue in the groups. Participants are invited to engage in dialogue and reflection on their health by means of open-ended questions. HCP invite participants to reflect on questions about how they experience their life-situation and their own perception of how their health can be enhanced, working inductively from the point of view of the singular person at the same time as one focuses on the shared experiences in the group.

The involved persons are encouraged to be active participants in researching their health with the following questions in mind: What is it that contributes to your capability to handle the symptoms and the consequences of illness, and what contributes to your wellness in your life situation? When patients are working on such questions, their answers and the information they are collecting are equally important to the information gathered by HCP. It has to do with developing a partner-relationship with the person and to elicit their tacit knowledge of health as well as to find relevant solutions together on what it is that contributes to the person's movement to the healthy pole of the health ease/dis-ease continuum [10, 37]. Patients' process of health promotion is facilitated by HCP active listening, and by supporting, comforting, and challenging the participants understanding of their situation. In addition, questions inspired by solution-focused therapy are used in order to facilitate the person's perspectives towards health within illness [19].

The written pedagogical tools in BKP that complement the intervention group work include a poster and a booklet/diary. The poster offers an overview of the phases of Bodyknowledging. The 40-page booklet describes the Bodyknowledging process illustrated by citations from former patients who were engaged in the research on the development of the Bodyknowledging framework. Intervention patients are encouraged to review specific parts of the booklet between the sessions and to reflect on study questions. There are blank pages available to write down reflections. The pedagogical tools imply that patients are engaged in dialogue on their self-care and health in a variety of ways, such as the dialogue with the text on the poster and booklet/diary, the dialogue between patients in the group and with HCP.

HCP leading BKP groups, introduce physical exercises at the beginning of each session to support the participants in the recognition of their bodily knowledge as a resource for health. Exercises are inspired by the physiotherapeutic method of basic body awareness therapy, which concentrates on breathing, balance, and movement $[40,41]$. Then, the HCP provides a short introduction to the BKP framework and patients are invited to reflect upon, and discuss questions posed in the booklet connected to each phase; drawing on principles of open dialogue and solution-focused therapy [37, 42, 43]. Facilitation of individual resources for health, physical activity, and social participation is emphasized as 
participants are supported by interdisciplinary HCP to work systematically on their health by attending to the phases described in the theoretical framework [23, 33, 34]. Herein lies the possibility to activate more of the persons' resources for health promotion and to explore challenges they may have with conducting self-care and self-management.

Bodyknowledging theory describe the grieving and anger as a part of an overall health promoting process in people with chronic illness and when used in the BKP intervention, one explicitly turns the attention of both patients and HCP to the importance of working through the uncertainty, losses, grieving, and anger in order to move towards better health. BKP offers the participating patients time and space to share their story and their experience of handling their life with illness, and HCP leading the groups have the responsibility to ensure a balance between the focus on deficits and the focus on health in the sessions.

Participants are also asked to choose a physical activity to do at home twice a week, and questions concerning these activities are posed in subsequent sessions to support them to conduct physical activity as a part of their health promotion efforts [44]. The purpose of the exercises was also to find the balance of stress, activity, and rest to prevent the outburst of relapses.

\subsubsection{Methods for the Development and Trials of BKP}

Initially, three clinical units were chosen for developing the new intervention: a rehabilitation unit, an outpatient clinic and a center for patient education. An interdisciplinary team of nine health care personnel representing the sites (nurses, occupational therapists, physiotherapist) and patients diagnosed with a variety of longterm chronic health conditions engaged with the principal investigator in the formative research [45, 46]. Criteria for reporting the development and early piloting of complex interventions [47] in health care was applied as a guide to outline each component of the intervention.
A comprehensive description of the foundation for BKP and the formative research has been published elsewhere [32]. The BKP has been piloted and implemented in specialist and community health care settings in several projects in Norway. Qualitative interviews and focus-group interviews with participating patients and HCP were used to collect data to explore their experiences of being engaged in the intervention, for evaluating the intervention structure, content, and means and to identify possible healthrelated outcomes. Qualitative process evaluation [46], content analysis [48, 49], and Interpretive Phenomenological Analysis (IPA) [50] were applied in different trials of BKP. Quantitative data were collected by means of Antonovsky's Sense of Coherence [51] questionnaire and the Outcome Rating Scale [52]. In addition, a brief evaluation form was filled in by patients. More details on methods and outcomes are provided in the next section.

\subsection{Patient-Reported Outcomes of Improvement in Empowerment and Health}

\subsubsection{Clinical Trials in Specialist Health Care}

The Bodyknowledging Program was first implemented in specialist care in Norway; in a specialist Rehabilitation unit, in an Outpatient Clinic for the follow-up of patients with Inflammatory Bowel Disease (IBD), and in a Center for Patient Education in chronic illness (CPE). A study sample of 31 men and 21 women $(n=52)$ ranging in age from 22 to 88 years volunteered to participate in the pilot-implementation. The diagnoses represented in the sample were Chronic Obstructive Pulmonary Disease, Heart Disease, Chronic Inflammatory Bowel Disease, Stroke, Multiple Sclerosis and other neurological or functional limitations without a specific diagnostic label. Patients varied in functional capacity and in time since diagnosis, but all had been ill for 1 year or more and had illness-related problems that were difficult to manage. The BKP was applied in 
group and in individual formats as a generic program to facilitate self-care, health, and recovery.

The intervention was implemented successfully across gender, ages, diagnostic categories, and clinical sites. The process evaluation included in-depth interviews with 34 patients after completing the BKP; of these, 25 patients engaged in 4 group interviews and 9 patients were interviewed individually. The research questions were: How do participants experience the program? What health-related changes, if any, can be attributed to the program? What are the interventions active ingredients, contributing to change?

Participants described that the BKP allowed them to work systematically on their health as a process and reported that because the Bodyknowledging framework is based on patient narratives, it is easy to understand. They evaluated the structure of the program as appropriate across clinical sites and saw the mix of men and woman and of people with different long-term conditions as positive because it created rich possibilities for sharing experiences and ideas about how to handle challenges and how to promote health while living with chronic illness. Participants emphasized that beginning with weekly sessions helped establish a good process. While the group format made it possible to relate one's own experiences to those of others, the individual format allowed more direct, in-depth work on each person's process.

Five themes captured participants' experiences of change in coping and health promotion abilities: (1) changed perspectives on health and illness, (2) new ways of thinking and acting towards the illness, (3) understanding situations, choices, and actions that make the health condition better or worse, (4) widening one's life space-being more active, and (5) communicating differently about health-related matters [38].

Changes in patient perspectives was connected to having a shared world of experience with others who were struggling with symptoms of illness. Because the BKP and its pedagogical tools contain a description of the life worlds of those with long-term health problems, the program offered comfort and support in the midst of pain. It also relieved a feeling of alienation created by the illness. A man attending individually in the outpatient clinic explained how his perspective of health and illness had changed through BKP:

I have seen a way through all the pain and anguish. When you read about the other patients' experiences, your own experience is being confirmed and in this way you do not feel so lonely. You understand that there are other persons who have managed and that there is a way through it all.

A woman attending the program individually at the rehabilitation unit described her new ways of thinking and acting after program completion:

The program has helped me to think in another way and to come out and to participate in life again. If I am completely honest with myself, the things I want to do are not impossible. It just takes more time, and that was absolutely not how I was thinking before I entered this program.

By attending to the Bodyknowledging process, participants could compare their own experience and choices to concepts and phases offered in the BKP's "insider" perspective. The theoretical framework helped them assess "where they were at the moment" and use that assessment to move on in their own process of health promotion. While still being well aware of the limitations imposed by illness, they were more aware of the risk of imposing unnecessary limitations upon themselves-how that could worsen their health-and they were able to think differently and more positively about their own capabilities. A man attending the program in a rehab group (stroke survivor) described how his engagement in BKP changed his understanding of the situations, choices, and actions that make the health condition better or worse.

I know my body better now. I listen to my body. I have learned how I feel when I am tired. Then I take a break before I begin again. It's much easier when you have a program to follow, such as this program-it works. I have gotten much more patient with myself. I try to be positive because then, it is easier to manage and to conduct what I want to do. I have learned that there are many possibilities even if I have a handicap. Even if everything goes more slowly than before, I am able to do the same as before. 
A woman attending individually in the outpatient clinic described how she had changed her way of handling her life situation with chronic illness:

\begin{abstract}
It has become clear to me that I have been escaping from the illness, but this summer I have taken a grip of the situation. I have told about the illness in my workplace, and now I am in a process of defining how much I should work and how. I am trying to reduce the demands I put on myself in order to prevent new relapses, because I know that when I work too much, I get exhausted and then the illness is worsened.
\end{abstract}

Discovering one's "own standards" was an important part of the participants' improved knowledge. Making this discovery was connected to taking one's levels of tolerance-for certain types and magnitudes of social and physical activity - seriously. Participants identified the ability to say no to oneself and to other people as an important strategy for promoting wellness. As the program encouraged participants to reflect critically on their ways of being, they engaged in a sort of "research process" concerning their own health. With the support of the program, their peers, and the health care personnel, they discovered their own strategies for self-care and what they could do to stay healthy. Widening one's life space-being more active was an important result in this regard. A woman attending a group at the CPE described how she learned to handle the dynamic balance between accepting one's limits and finding new possibilities for activities:

I am more conscious that I, in spite of my limitations, I can manage to have a nice time. I cannot climb the mountains anymore, but this summer, I was riding a horse on a camp in the mountains, so it is all about compensation. Now, in the winter holidays, I was on the mountain with my friends. They went skiing and I was walking, and we had a good time together.

Participants said that being in the program was like "coming out of a vacuum." They used the concepts and phases of the Bodyknowledging model to sort out their chaos, find meaning in their experience, and move on to new phases. The search for meaningful substitutes for pre-illness activities was a central strategy for achieving health within illness. Communicating differently about health related matters was described as an important outcome. At the onset of BKP, participants were concerned with how to tell people about their health condition and how to handle reactions from coworkers, employers, friends, and family. A man whose functional limitations were "invisible" to others described his experience of this:

Before, I got angry, and was not able to put my reactions in words. The program has helped me to say something about my experience with the illness and has helped me to have better relations with my family.

Participants appreciated the opportunity to open up and work on the difficult parts of their lives in a safe setting. Getting feedback from HCP (and peers if in a group) challenged their own understanding and constituted a time for learning. As a result, participants described being stronger in social encounters, in the sense that they were learning to tell to others how they felt and what they had to consider in order to stay well.

Patients' active engagement in the Bodyknowledging Program, the HCP's attitudes and approaches, the group work and the conceptual framework of Bodyknowledging were identified as the interventions' active ingredients [38].

\subsubsection{Trials of the BKP Intervention in Community Care}

Similar findings to those reported in specialist health care, was identified in a study of the feasibility and outcome of the BKP in community care in Norway [53]. In one of the studies, a sample of 3 men and 8 women $(n=11)$ between the ages of 30 and 60 volunteered to participated in 2 BKP groups. Data were collected in individual and group interviews and analyzed according to Interpretative Phenomenological Analysis (IPA). Participants described their engagement in the $\mathrm{BKP}$ as an enlightening experience that contributed to positive change, personal growth, and better health. Themes like changes in self-awareness, changes in attitudes, awareness of one's body, accepting one's limited capacity, making priorities and setting boundaries, letting go of shame, and regaining control were themes that 
came up in the analysis. The patterns of themes indicate that participating in BKP contributed to a change in the participants' perceived locus of control, taking it from external to internal [53]. This is an essential finding, as perceived internal control is necessary in order for patients to be in charge of their own health.

In another study of the efficiency of BKP in community care, the Outcome Rating Scale (ORS) was used to measure patients' self-reported recovery repeatedly at baseline, after four sessions of BKP and after program completion [54]. Four dimensions were assessed: (1) individual (personal or symptomatic distress and well-being), (2) interpersonal (relational distress or well-being), (3) social (patient satisfaction with work, school, and relationships), and (4) overall (general sense of well-being). The sample comprised of 13 men and 14 women who had been diagnosed with a range of long-term conditions. The mean age was 54 years. Participants reported significant changes in recovery and health throughout the program period. The total change in average ORS for the whole sample $(n=27)$ was $4.6(\mathrm{SD}=7.6 ; p<0.001)$. There was an observed improvement from $t_{0}$ to $t_{1}$ with a mean change of 3.5 $(\mathrm{SD}=4.8 ; p=0.005)$. The change did not reverse from $t_{1}$ to $t_{2}$ with a mean improvement from session 4 to session 7 of 1.3 ( $\mathrm{SD}=5.7 ; p=0.003)$. The greatest change was in the personal and general well-being dimension of ORS. These findings demonstrate that the BKP intervention contributed to an improvement of dysfunctional patients from below to above the ORS cut-point of 25 .

\subsubsection{Comparison of Outcomes in Specialist and Community Health Care}

A study evaluated the impact of BKP on SOC in two samples; (1) patients in the specialist health care and (2) patients in community care context. Both samples completed BKP [55]. The baseline sample included 108 Norwegian adults (aged 21-89). A variety of diagnostic categories were represented in the sample such as neurological diseases (i.e. epilepsy, multiple sclerosis, Parkinson's), musculoskeletal pain, stroke, psy- chological problems like anxiety and depression, diabetes, heart failure, COPD, and IBD diagnosed with somatic and/or psychological health problems. Both community and specialist care participants were equally represented in the sample with a fairly equal distribution of men (51\%) and women (57\%). Community and specialist care participants were included and equal proportions of men and women were represented (51\% v. 57\%). SOC mean score in the total sample increased from a baseline of 135.3-137.6 (mean change 2.3) at program completion (after 12 weeks) which confirms the possibility for patients with chronic illness to strengthen their self-care, self-management and health as they engage in BKP sessions. The manageability and comprehensibility dimensions also improved, whereas the meaningfulness dimensions remained relatively stable. Participants' SOC increased in both settings, with a larger mean change found in community care. The paired sample $t$-test demonstrate strong evidence for a difference in women's manageability subscales from baseline to follow-up ( $n=61$; mean change $=4.7$; $p<0.05)$. Significant changes in SOC and manageability subscales were also found for participants with children $(n=72)$. Similar patterns of positive manageability changes were identified for participants living with a partner and public transfer payment (i.e., pension) recipients [55]. These findings indicate that BKP is an intervention that function to strengthen individual resources and strategies for health in chronic illness.

\subsection{Discussion}

We are facing an epidemic of chronic illness and comorbidity [56, 57] and the situation calls for new perspectives and approaches in health promotion work. However, the field of health promotion in chronic illness is still at the start of its development. The challenge is to move our perspective from focusing heavily on the problem of disease, disability, medical treatment, and care towards the person's and their family's strengths and capability for promoting health within illness [24]. This implies a further development of the holistic paradigm suggested by 
Engel [58] decades ago, outlined by WHO as the biopsychosocial model [57] and to use more person-centered approaches as this is widely acknowledged as helping people living well with a chronic condition [59]. In this paradigm, the health care system and the HCP function as supervisors and facilitators for health, while the person and their family are in charge of the health promotion endeavor. Now, the person at risk for or diagnosed with chronic illness is placed at the center and in an active position as the most important health promotion agent in their life and as an equal partner in the health promotion team. Significant others are invited to participate in supporting the person in their health promotion process. The aim is to facilitate the person's resources for health at the same time as the treatment of the health condition is taken care of. New models and interventions are needed in order to operationalize the values of person-centeredness and empowerment in practice.

The Bodyknowledging program is an example of such new approaches entailing a personcentered approach focusing on activating and utilizing patients' inherent resources for health [23, 60, 61] (i.e. their embodied knowledge of limits of tolerances for activity and factors of the physical and psychosocial environment with an impact on the condition). The research grounding BKP demonstrates that patient's experience-based knowledge constitutes a critical but underutilized resource for the prevention of deterioration and for the promotion of health in chronic illness [22, 29, 34]. The following example illustrates how the BKP functions in this regard:

Today, my body "told me" that I am not capable of driving a car because my head is not quite fit today. In the past, I was pushing myself to drive and then, something bad could happened. Still, it is important to push oneself forward, but in the right mode, because there are many ways to push oneself. It is like stretching a rubber band. You can stretch it, but if you stretch too hard, it breaks. That has happened to me. I have learned a lot about myself and my reactions. I got the possibility to tell the health care personnel in the program about it and I got a picture of it (the process) and I have learned that I must allow myself to be sad sometimes. It has been so important to me to learn that I don't have to be clever all the time (Woman with disability).
The example above elicits the person's knowledge of dynamic limits of tolerances and the usefulness of the Bodyknowledging model as a tool to assess one's health capacity and position on the health ease/dis-ease continuum in a given moment or period of time [10]. Bodyknowledging theory [23] elicits how movement in the direction of health depends on a balance between deficits and resources and on the person's active engagement in reflection and action towards better health. The dialogue with health professionals is important as the professionals posit medical and scientific knowledge and clinical experience on many of the issues people with chronic illness are facing. When patients and HCP share their knowledge and experience, they discover which factors in the environment (food, drink, social relations, activity, and so on) that one must become less exposed to or avoid, and what factors that contribute to individual health. Equal respect for the patient's and professional's different types of knowledge is a necessary condition for the dialogue to function as a health promoting window of opportunity [62-64].

People living with chronic illness have a lot in common as they try to live their lives as best they can and stay healthy while living with an illness. However, patient education and wellnessinterventions in the context of chronic illness are often specific to particular diagnostic groups and not designed to be applied across diagnostic categories $[65,66]$. The BKP program fills a gap in this regard as it is designed to be used across different diagnoses, clinical settings, and health disciplines [32].

\subsubsection{The Unique Contribution of the Bodyknowledging Program}

\subsubsection{Reflects Patient's Perspective of Living with Chronic Illness and Their Process of Health Promotion}

BKP is new and different from other approaches because the theoretical framework reflects the patient's perspective of living with chronic ill- 
ness and their process of health promotion [23, 33]. It is different because Health care personnel who are leading BKP groups are working within a patient-based framework which "reflects" the patients' "world," replacing the professionals stand to be facilitators for health within the patient-defined framework. When Bodyknowledging is used as a backdrop, this functions as a key to open a new door to "a room of recovery" meaning that BKP participants can come forward with their experiences with the illness, health strategies, and hopes for the future as well as their worries and challenges [24, 54]. This provides a foundation for addressing individual challenges of living with chronic illness and to discover individual possibilities for the promotion of health within illness.

\subsubsection{Focus Is on Activating Individual Resources for Health: Not on Illness}

The BKP interventions' main focus is how individual resources for health can be activated and facilitated by attending to the sick body as a resource for health $[23,35,60,64]$. This adds to the development of the field of health promotion in the sense that the body is thematized as an expressive, meaningful source of knowledge $[35,36]$. When participants are working systematically on the phases of Bodyknowledging, they are assisted in recognizing their altered body as a resource for health as well as in finding words to describe their life situation and to find ways of handling the challenges that confront them. The main message is that the ill persons' process of Bodyknowledging strengthens their resources for handling their life with illness.

\subsubsection{Patients' Bodily Knowledge Is Seen as Part of Their Generalized Resistant Resources}

The BKP program adds and incorporates patients' bodily knowledge to the description of Generalized Resistant Resources by Antonovsky [10]. The phenomenological understanding of the body is important in this regard, that is; the body as a foundation for existence and under- standing, and the body as a subject that carries the meaning and expression of the person's life $[35,64,67]$. In this holistic paradigm, the person's ongoing process of listening and understanding the body's signs is equally important to biomedical tests and "outside" observations of the physical body [67-69]. The core of the BKP is the acknowledgement, facilitation and utilization of the patients' bodily knowledge of health and illness [32, 60, 61].

\subsubsection{Sharing of Lay Bodily Knowledge as Part of Self-Management in Chronic Illness}

However, this knowledge is not "inserted" or "taught" them by HCP or peers, as the knowledge is created by means of Bodyknowledging which is a natural process that goes on within them [23, 33]. This unique but undervalued knowledge is recognized and strengthened through the person's engagement in the intervention and through a dialogue characterized by knowledge, understanding and hope [33]. Lorig's research [70] has confirmed the importance of the sharing of lay knowledge as a part of self-management in chronic illness. However, patients' bodily knowledge in chronic illness was not described as a resource for health in the Chronic Disease SelfManagement Program (CDSM) or the like.

\subsubsection{Special Attention to the Psychosocial Dimensions of Health and Relational Support}

The BKP adds by demonstrating the effects of using a framework that elicits patients' bodily knowledge of health as a resource for selfmanagement $[54,55]$ and as a tool to promote shifts from having "illness in the foreground" to having "health in the foreground" [19]. Participants described that "to be healthy within illness" implied coming out of a vacuum and to participate in life again. This applied to different areas of life, including family life, working life, and social life. These findings indicate that the BKP attends especially to the psychosocial dimensions of health in individuals with chronic 
illness and relational support [38, 53, 54]. According to Dwarswaard et al. [71] relational support is at the center of the support needs and fuels all other types of support. This was confirmed in a systematic review concluding that for COPD self-management to be effective, patients' psychosocial needs must be prioritized alongside medication and exacerbation management [72].

\subsubsection{Provides Tools for Participants to Assess Their Responses to Long- Term Illness}

The Bodyknowledging Program contains tools for participants to assess their responses to longterm illness and to discover how they can impact their health positively by using their own and their environment's resources. The BKP presents inherent patient expertise (the phases of Bodyknowledging) to be interpreted and applied by patients participating in BKP. This approach is in keeping with Paulo Freire's [37] "pedagogy of the oppressed" in which the person defines their situation and in which dialogue serves as the main method for helping people understand their situations and to act in new ways. This seems to have a liberating effect as the solutions are the person's and not based on predefined skills by professionals. By attending to the different phases described in the Bodyknowledging framework, patients are empowered and healthy transitions are facilitated, that is; a person's feeling of being connected and socially supported, as well as their perceived confidence, coping, and subjective well-being are actively restored [73, 74]. These findings align with a review of what difference empowerment makes to the health and well-being of individuals [27].

\subsubsection{Emphasis Is Laid on Health as a Dynamic Continuum}

Patients' engagement in BKP, the health care personnel's attitudes and approaches, the group work, and the conceptual framework of Bodyknowledging were identified as this interventions' active ingredients [38]. Emphasis is put on the participants' process of health as a dynamic continuum [10] while living with chronic illness. When personal knowledge of health and illness is acknowledged, this affects the assessment of their situation as well as their way of handling the challenges. The experience of symptoms is not so threatening when they know more about the meaning of their ailments (comprehensibility), how to relieve them and how to prevent relapses (manageability). The uncertainty is lessened and their experience of having bodily control and safety gets stronger, which has a positive effect on the person's ability to handle their life situation with chronic illness. This adds to the theory of salutogenesis [10] by eliciting that the person's embodied knowledge of health and illness represents a great but unheeded resource for coping, recovery, and health in chronic illness [23, 33].

\subsubsection{Evidence of BKP Health Promoting Outcomes}

Findings indicate that the Bodyknowledging Program serves as an intervention to strengthen health and empowerment across diagnostic categories, age, and gender and is suitable both in specialist and community health care [55]. Health-related outcomes of BKP like changed perspectives on health and illness, new ways of thinking and acting towards the illness, understanding situations, choices, and actions that make the health condition better or worse, widening one's life space-being more active, and communicating differently about health-related matters [38] indicate that participating in BKP contributed to a change in the participants' locus of control, taking it from external to internal [53]. Based on these findings one can argue that the BKP contributed to perceived control of illness-related strain and circumstances. The findings are in line with the goal of health promotion which is exactly to increase the involved persons' control over their health and to improve it [1]. Patients in the municipality health care expressed that the BKP represented a new and different encounter with the health care system and suggested that the program should be extended with more sessions and a follow-up period lasting for 6 months [53]. 


\subsection{Implications for Practice}

The Bodyknowledging theory and program can be used in the education of HCP to elevate their understanding of the lay-perspective and to gain insight into the patients' process of health promotion in chronic illness. The BKP offers shared concepts for interdisciplinary work and patient participation. The model can be applied by HCP and patients diagnosed with chronic illness as a tool to assess the patients' position in their health promotion process and as a tool for patient activation and dialogue in health care encounters. The Bodyknowledging Program is recommended to be used as a broadly applicable intervention in health promotion work in community health care settings as well as in hospitals, in outpatient clinics, or in rehabilitation units as part of the followup of patients at risk or diagnosed with chronic illness.

\subsection{Conclusion}

This chapter emphasizes the need for developing the field of health promotion in chronic illness by developing interventions that operationalize the values of person-centered and holistic health in practice. A change of focus is needed from focusing heavily on disease and behavioral change to mobilizing patients' intrinsic resources and capabilities for health in chronic illness. Patients' bodily knowledge of health and illness are elicited as an unutilized resource in this regard. The Bodyknowledging program (BKP) is introduced as an example and a broadly applicable intervention to support patients to take charge of their own health. Some studies and positive outcome of trials of BKP in Norway are described. There is a need to evaluate the feasibility and acceptability of BKP internationally in patient samples with a range of chronic illnesses. Such studies are well-positioned to contribute key research findings relating to the mobilization of under-utilized patient capacities for health and well-being. These findings will be important for improving the quality of person-centered care within clinical practice and will set the stage for further work that will be poised to improve longer-term public health outcomes for chronic illness.

\section{Take Home Messages}

- The field of health promotion in chronic illness is in need of further development to ensure a strong focus on how to promote health within illness. The Bodyknowledging Program (BKP) is an example of interventions that aim to activate and utilize patients' inherent resources for health while living with chronic illness.

- Bodyknowledging theory serve as the framework for BKP. The theory elicits how experiences of illness and vulnerability can be turned into assets for health, and how the patient becomes empowered by utilization of their inherent resources for health.

- Patients engaged in the BKP report that their ability to handle distress, conduct self-care, and promote health was improved. This had a positive impact on their relationships to significant others and their participation in society.

\section{References}

1. Leddy S. Integrative health promotion: conceptual bases for nursing practice. Massachusetts: Jones \& Bartlett Learning; 2006.

2. Larsen PD. Lubkin's chronic illness. Impact and intervention. 10th ed. Massachusetts: Jones \& Bartlett Learning; 2019.

3. World Health Organization. Global status report on noncommunicable diseases 2010. Geneva: WHO; 2011.

4. Kralik D, Paterson B, Coates V. Translating chronic illness research into practice. Hoboken: Wiley; 2010.

5. World Health Organization. The world health reportprimary health care. Geneva: WHO; 2008.

6. Hajat C, Stein E. The global burden of multiple chronic conditions: a narrative review. Prev Med Rep. 2018;12:284-93.

7. Navickas R, Petric VK, Feigl AB, Sychell M. Multimodbidity: what do we know? What should we do? J Comorbid. 2016;6(1):4-11.

8. Benner P. Interpretive phenomenology. Embodiment, caring and ethics in health and illness. Thousand Oaks: Sage; 1994.

9. Kaplun A, editor. Health promotion and chronic illness. Discovering a new quality of health. Cologne: WHO Regional Publications; 1992. 
10. Antonovsky A. Unraveling the mystery of health: how people manage stress and stay well. San Fransisco: Jossey-Bass; 1987.

11. Mittelmark MB, Sagy S, Eriksson M, Bauer GF, Pelikan JM, Lindström B, et al. The handbook of salutogenesis. London: Springer Nature; 2017.

12. Lillefjell M, Jakobsen K, Ernsten L. The impact of a sense of coherence in employees with chronic pain. Work. 2015;50:313-22.

13. Nilsen V, Bakke P, Rohde G, Gallefoss F. Is sense of coherence a predictor of lifestyle changes in subjects at risk of type 2 diabetes? Public Health. 2015;129:155-61.

14. Ko D, Bratzke L-C, Roberts T. Self-management assessment in multiple chronic illness: a narrative review of literature. Int J Nurs Stud. 2018;83:83-90.

15. Richards AA, Shea K. Delineation of self-care and associated concepts. J Nurs Scholarsh. 2011;43(3): 255-64.

16. Leenerts MH, Magilvy JK. Investing in self-care: a midrange theory of self-care grounded in the lived experience of low-income HIV-positive white women. Adv Nurs Sci. 2000;22(3):58-75.

17. Thorne S, Paterson B, Russel C. The structure of everyday self-care descision making in chronic illness. Qual Health Res. 2003;13(10):1337-52.

18. Richards AA, Kimberley S. Delineation of selfcare and associated concepts. J Nurs Scholarsh. 2011;43(3):255-64.

19. Paterson BL. The shifting perspectives model of chronic illness. J Nurs Scholarsh. 2001;33(1):21-6.

20. Brooks HL, Rogers A, Sanders C, Pilgrim D. Perceptions of recovery and prognosis from longterm conditions: the relevance of hope and imagined futures. Chronic Illn. 2015;11(1):3-20.

21. Miller J. Coping with chronic illness: overcoming powerlessness. 2nd ed. Philadelphia: F.A. Davis; 1992.

22. Wilde MH. Embodied knowledge in chronic illness and injury. Nurs Inq. 2003;10(3):170-6.

23. Heggdal K. Utilizing bodily knowledge in patients with chronic illness in the promotion of their health: a grounded theory study. Calif J Health Promot. 2013;11(3):62-73.

24. Gottlieb LN. Strengths-based nursing care: health and healing for person and family. New York: Springer Publishing Company; 2013.

25. World Health Organization. Health promotion and chronic illness. Discovering a new quality of health. England: WHO Regional Office for Europe; 1992.

26. WHO. Global strategy for health for all by 2000 . 1989. Report no.: 3.

27. Woodall J, Raine G, South J, Warwich-Booth L. Empowerment, health and well-being; 2010.

28. Bossy D, Knutsen IR, Rogers A, Foss C. Moving between ideologies in self-management support-a qualitative study. Health Expect. 2018;22:83-92.

29. Thorne SE, Ternulf Nyhlin K, Paterson BL. Attitudes toward patient expertise in chronic illness. Int J Nurs Stud. 2000;37(4):303-11.
30. Wagner EH, Austin BT, Davis C, Hindmarsh M, Schaefer J, Bonomi A. Improving chronic illness care: translating evidence into action. Health Aff. 2001;20(6):64-78.

31. McCormack B, Borg M, Cardiff S, Dewing J, Jacobs G, Janes N, et al. Person-centredness-the 'state' of the art. Int Pract Dev J. 2015;5(Suppl):1-15.

32. Heggdal K. 'We experienced a lack of tools for strengthening coping and health in encounters with patients with chronic illness': bridging theory and practice through formative research. Int Pract Dev J. 2015;5(2):4.

33. Heggdal K. Kroppskunnskaping-En grunnleggende prosess for mestring ved kronisk sykdom [Bodyknowledging - a basic process of coping with chronic illness]. PhD thesis. Bergen: University of Bergen; 2003.

34. Heggdal K. Kroppskunnskaping: pasienten som ekspert i helsefremmende prosesser. [Bodyknowledging-patients as experts in health promotion processes]. Oslo: Gyldendal Academic Publisher; 2008.

35. Merleau-Ponty M. The phenomenology of the body. Oslo: Pax; 1994.

36. Merleau-Ponty M, Smith C. Phenomenology of perception. New Delhi: Motilal Banarsidass Publisher; 1996.

37. Freire P. Pedagogy of the oppressed. 30th anniversary ed. New York: The Continuum; 2006.

38. Heggdal K. Patient's experience of the outcomes of engaging in a broadly applicable health promotion intervention for individuals facing chronic illness. Health. 2015;7:765-75.

39. Naidoo J, Wills J. Health promotion: foundations for practice. 2nd ed. Edinburgh: Elsevier Health Sciences; 2000.

40. Dropsy J. Den Harmoniska Kroppen. Stockholm: Natur och Kultur; 1988.

41. Gard G. Body awareness therapy for patients with fibromyalgia and chronic pain. Disabil Rehabil. 2005;27(12):725-8.

42. Anderson H, Goolishian H. The client is the expert: a not-knowing approach to therapy. In: McNamee S, Gergen K, editors. Therapy as social construction. London: Sage; 1992. p. 25-39.

43. O'Connel B. Solution-focused therapy. 3rd ed. London: Sage; 2012.

44. Healthy People. Healthy people 2020. 2015. https:// www.healthypeople.gov/.

45. Möhler R, Bartoszek G, Köpke S, Meyer G. Proposed criteria for reporting the development and evaluation of complex interventions in healthcare (CReDECI): guideline development. Int J Nurs Stud. 2012;49(1):40-6.

46. Patton MQ. Qualitative evaluation and research methods. 3rd ed. Thousand Oaks: Sage Publications; 2002.

47. Campbell M, Fitzpatrick R, Haines A, Kinmonth AL. Framework for design and evaluation of complex interventions to improve health. Br Med J. 2000;321(7262):694-6. 
48. Graneheim UH, Lundman B. Qualitative content analysis in nursing research: concepts, procedures and measures to achieve trustworthiness. Nurse Educ Today. 2004;24(2):105-12.

49. Graneheim UH, Lindgren BM, Lundman B. Methodological challenegs in qualitative content analysis: a discussion paper. Nurse Educ Today. 2017;56:29-32.

50. Smith JA, Osborne M. Interpretive phenomenology analysis. London: Sage Publications; 2008.

51. Eriksson M, Linstrøm B. Validity of Antonovsky's sense of coherence scale: a systematic review. J Epidemiol Commun Health. 2005;59:460-6.

52. Miller SD, Duncan BL, Brown J, Sparks JA, Claud DA. The Outcome Rating Scale: a preliminary study of the reliability, validity, and feasibility of a brief visual analog measure. J Brief Ther. 2003;2: 91-100.

53. Engevold MH, Heggdal K. Patients'experiences with changes in perceived control in chronic illness: a pilot study of the outcomes of a new health promotion program in community health care. Scand Psychol. 2016;3:e5.

54. Heggdal K, Oftedal B, Hofoss D. The effect of a person-centred and strength-based health intervention on recovery among people with chronic illness. Eur J Person Centered Healthc. 2018;6(2):279-85.

55 . Heggdal K, Lovaas B. Health promotion in specialist and community care: how a broadly applicable health promotion intervention influences patient's sense of coherence. Scand J Caring Sci. 2019;32(2):690-7.

56. National Health Council. About chronic diseases. 2014. www.nationalhealthcouncil.org/sites/default/ files/AboutChronicDisease.pdf.

57. Martz E. Promoting self-management of chronic health conditions. Theories and practice. Oxford: Oxford University Press; 2018.

58. Engel GL. The need for a new medical model: a challenge for biomedicine. Science. 1977;196(4286): 129-36.

59. Zoffmann V, Hörnsten A, Storbækken S, Graue M, Rasmussen B, Wahl A, et al. Translating personcentered care into practice: a comparative analysis of motivational interviewing, illness-integration support and guided self-determination. Patient Educ Couns. 2016;99:400-7.

60. Benner P, Wrubel J. The primacy of caring. Stress and coping in health and illness. Menlo Park: AddisonWesley; 1989.
61. Toombs SK. The meaning of illness: a phenomenological account of the different perspectives of physician and patient. Dordrecht: Kluwer Academic Publishers; 2013.

62. Thorne S. Patient-provider communication in chronic illness: a health promotion window of opportunity. Fam Commun Health. 2006;29(1):4-11.

63. Kirkengen AL. Inscribed bodies. Health impact of childhood sexual abuse. Dordrecht: Kluwer Academic; 2001.

64. Carel H. Phenomenology as a resource for patients. J Med Philos. 2012;37(2):96-113.

65. Lorig KR, Holman HR. Self-management education: history, definition, outcomes, and mechanisms. Ann Behav Med. 2003;26(1):1-7.

66. Stuifbergen AK, Morris M, Jung JH, Pierini D, Morgan S. Benefits of wellness interventions for persons with chronic and disabling conditions: a review of the evidence. Disabil Health J. 2010;3(3):133-45.

67. Carel H, Kidd IJ, Pettigrew R. Illness as a transformative experience. Lancet. 2016;388(10050):1152-3.

68. Frank AW. The wounded storyteller: body, illness, and ethics. Chicago: University of Chicago Press; 2013.

69. Svenaeus F. The hermeneutics of medicine and the phenomenology of health: steps towards a philosophy of medical practice. Linköping: Department of Health and Society, Linköping University; 1999.

70. Lorig KR, Ritter P, Stewart AL, Sobel D, Brown BW, Bandura A, et al. Chronic disease self-management program: 2-year health status and health care utilization outcomes. Med Care. 2001;39(11):1217-23.

71. Dwarswaard J, Bakker EJM, Staa AL, Boeije HR. Self-management support from the perspective of patients with a chronic condition: a thematic synthesis of qualitative studies. Health Expect. 2015;19:194-208.

72. Russel S, Oladapo J, Ogunbayo J, Newham JJ, Marshall-Heslop K, Netts P, et al. Qualitative systematic review of barriers and facilitators to selfmanagement of chronic obstructive pulmonary disease: views of patients and healthcare professionals. Prim Care Respir Med. 2018;28(1):2.

73. Meleis AI, Sawyer LM, Im EO, Hilfinger Messias DK, Schumacher K. Experiencing transitions: an emerging middle-range theory. Adv Nurs Sci. 2000;23(1):12-28.

74. Halding A-G, Heggdal K. Patients' experiences of health transitions in pulmonary rehabilitation. Nurs Inq. 2012;19(4):345-56. 
Open Access This chapter is licensed under the terms of the Creative Commons Attribution 4.0 International License (http://creativecommons.org/licenses/by/4.0/), which permits use, sharing, adaptation, distribution and reproduction in any medium or format, as long as you give appropriate credit to the original author(s) and the source, provide a link to the Creative Commons license and indicate if changes were made.

The images or other third party material in this chapter are included in the chapter's Creative Commons license, unless indicated otherwise in a credit line to the material. If material is not included in the chapter's Creative Commons license and your intended use is not permitted by statutory regulation or exceeds the permitted use, you will need to obtain permission directly from the copyright holder.

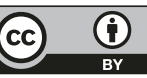

